\title{
Exploring adults' experiences of sedentary behaviour and participation in non- workplace interventions designed to reduce sedentary behaviour: a thematic synthesis of qualitative studies
}

\author{
G. H. Rawlings ${ }^{1}$, R. K. Williams² , D. J. Clarke ${ }^{2 *}$, C. English ${ }^{3}$, C. Fitzsimons ${ }^{5}$, I. Holloway ${ }^{4}$, R. Lawton ${ }^{6}$, G. Mead , \\ A. Patel ${ }^{8}$ and A. Forster ${ }^{2}$
}

\begin{abstract}
Background: Sedentary behaviour is any waking behaviour characterised by an energy expenditure of $\leq 1.5$ metabolic equivalent of task while in a sitting or reclining posture. Prolonged bouts of sedentary behaviour have been associated with negative health outcomes in all age groups. We examined qualitative research investigating perceptions and experiences of sedentary behaviour and of participation in non-workplace interventions designed to reduce sedentary behaviour in adult populations.
\end{abstract}

Method: A systematic search of seven databases (MEDLINE, AMED, Cochrane, PsychINFO, SPORTDiscus, CINAHL and Web of Science) was conducted in September 2017. Studies were assessed for methodological quality and a thematic synthesis was conducted. Prospero database ID: CRD42017083436.

Results: Thirty individual studies capturing the experiences of 918 individuals were included. Eleven studies examined experiences and/or perceptions of sedentary behaviour in older adults (typically $\geq 60$ years); ten studies focused on sedentary behaviour in people experiencing a clinical condition, four explored influences on sedentary behaviour in adults living in socio-economically disadvantaged communities, two examined university students' experiences of sedentary behaviour, two on those of working-age adults, and one focused on cultural influences on sedentary behaviour. Three analytical themes were identified: 1) the impact of different life stages on sedentary behaviour 2) lifestyle factors influencing sedentary behaviour and 3) barriers and facilitators to changing sedentary behaviour.

Conclusions: Sedentary behaviour is multifaceted and influenced by a complex interaction between individual, environmental and socio-cultural factors. Micro and macro pressures are experienced at different life stages and in the context of illness; these shape individuals' beliefs and behaviour related to sedentariness. Knowledge of sedentary behaviour and the associated health consequences appears limited in adult populations, therefore there is a need for provision of accessible information about ways in which sedentary behaviour reduction can be integrated in people's daily lives. Interventions targeting a reduction in sedentary behaviour need to consider the multiple influences on sedentariness when designing and implementing interventions.

Keywords: Sedentary behaviour, Sitting, Qualitative research, Physical activity, Thematic synthesis

\footnotetext{
* Correspondence: d.j.clarke@leeds.ac.uk

${ }^{2}$ Academic Unit of Elderly Care and Rehabilitation, Leeds Institute of Health

Sciences, Temple Bank House, University of Leeds, Bradford Royal Infirmary,

Bradford BD9 6RJ, UK

Full list of author information is available at the end of the article
}

(c) The Author(s). 2019 Open Access This article is distributed under the terms of the Creative Commons Attribution 4.0 International License (http://creativecommons.org/licenses/by/4.0/), which permits unrestricted use, distribution, and reproduction in any medium, provided you give appropriate credit to the original author(s) and the source, provide a link to the Creative Commons license, and indicate if changes were made. The Creative Commons Public Domain Dedication waiver (http://creativecommons.org/publicdomain/zero/1.0/) applies to the data made available in this article, unless otherwise stated. 


\section{Introduction}

Over the last decade, sedentary behaviour has emerged as an important public health issue. Sedentary behaviour has become the focus of research, clinical and policy interest. Evidence supporting the detrimental effects of prolonged sedentary time on health and wellbeing in individuals of all ages is rapidly growing [1-3]. In the general population, sedentary behaviour has been associated with an increased risk of a range of health problems including, cardiovascular conditions [4], mood disorders [5] and allcause mortality [6]. Some clinical populations, for example stroke survivors [7] or those living with frailty [8], are more prone to engage in long, uninterrupted bouts of sedentariness. This is likely to contribute to increased risk of adverse health outcomes and limit the potential of rehabilitation therapies.

Sedentary behaviour is defined as 'any waking behaviour characterised by an energy expenditure of $\leq 1.5$ metabolic equivalents of task while in a sitting, reclining or lying posture' (p.5). Sedentary behaviour is distinct from physical inactivity, which is defined as insufficient physical activity levels to meet current recommendations (150 min of moderate - vigorous physical activity a week) [9]. Previous systematic reviews related to sedentary behaviour have primarily focused on measurement of, determinants of and the health-related effects of sedentary behaviour, focused on interventions designed to reduce sedentary behaviour [10-12] or on whether physical activity is effective for offsetting the negative effects of sedentary behaviour [13]. These reviews explore intrapersonal, social, environmental, physical environmental and policy correlates of sedentary behaviour [14], and the relationship between sedentary behaviour and health-related quality of life. Systematic reviews of qualitative data are becoming more commonplace and have explored adults' experiences of physical activity [15] and acceptability of physical activity interventions [16]. Qualitative research can contribute to our understanding of factors that influence sedentary behaviour, assist with identification of modifiable determinants, and help identify barriers and facilitators to promoting sedentary behaviour change.

The aims of the current review were to produce a systematic, thematic synthesis of qualitative research investigating (i) adults' experiences of sedentary behaviour, and (ii) participation in interventions designed to reduce sedentary behaviour in adults. We sought to understand peoples' perceptions and experiences of sedentary behaviour in order to identify what barriers and facilitators influence sedentary behaviour in adults. As this review was undertaken as part of a research programme that will develop and test a community-based sedentary behaviour reduction intervention for stroke survivors, we excluded workplace-based studies.

We also aimed explore the views of carers, relatives and health and social care professionals in relation to sedentary behaviour in adults, however, we were not able to identify any data to directly address this aim.

\section{Methods \\ Search strategy}

This review has been undertaken in line with the Preferred Reporting Items for Systematic Reviews and Meta-Analyses (PRISMA) standards. The protocol was published on the PROSPERO database ID: CRD42017083436.

A systematic search of seven databases (MEDLINE, AMED, Cochrane Database of Systematic Reviews, PsychINFO, SPORTDiscus, CINAHL and Web of Science) was performed in September 2017. Search terms were developed in collaboration with an information specialist (Additional file 1). Inclusion and exclusion criteria are listed in Table 1.

Following the search, three reviewers (GHR, RW and DJC) jointly screened the first 150 titles and abstracts - this allowed for review and refinement of the inclusion criteria. Thereafter, GHR and RW independently screened the

Table 1 Inclusion and exclusion criteria

\begin{tabular}{|c|c|c|}
\hline Factor & Inclusion criteria & Exclusion criteria \\
\hline Purpose & Include focus on Sedentary Behaviour (SB) and/or reduction of SB. & $\begin{array}{l}\text { Focus on physical activity (PA) but does not explore SB or } \\
\text { sedentary time }\end{array}$ \\
\hline Sample & $\begin{array}{l}\text { Adults ( } \geq 18 \text { years), caregivers/friends/family in relation to SB in adults, } \\
\text { health care professionals specific to SB in adults. Adults must have had } \\
\text { first-hand experience of being sedentary and/or being involved in } \\
\text { programmes designed to change SB. }\end{array}$ & $\begin{array}{l}\text { Children or adolescents ( } \leq 17 \text { years), caregivers/family/friends in } \\
\text { relation to SB in children, paediatric health care professionals } \\
\text { Workplace-based studies }\end{array}$ \\
\hline $\begin{array}{l}\text { Data } \\
\text { collection }\end{array}$ & $\begin{array}{l}\text { Primary research studies using qualitative data collection methods for } \\
\text { example, study data may be generated through interviews, focus } \\
\text { groups, qualitative observational studies }\end{array}$ & Solely quantitative methods. \\
\hline $\begin{array}{l}\text { Data } \\
\text { analysis }\end{array}$ & Qualitative methodology e.g. thematic, content, framework & $\begin{array}{l}\text { Solely quantitative methods. Descriptive accounts where no } \\
\text { evidence of qualitative method or analysis }\end{array}$ \\
\hline Format & English and peer-reviewed. No date restrictions were applied & $\begin{array}{l}\text { Grey literature - posters, conference abstracts, supplements, } \\
\text { book chapters, case studies, reviews, dissertations/ thesis, } \\
\text { editorials }\end{array}$ \\
\hline
\end{tabular}


remaining titles and abstracts (50\% each). Full text articles were independently reviewed by the same two reviewers; disagreements were resolved through discussion with a third reviewer (DJC). A backward search of references of eligible papers did not identify any additional studies.

\section{Data extraction}

The following data were extracted from each study: author(s), year of publication, study purpose, sample characteristics, country, methodological considerations, findings and discussion. One-third of the included studies were randomly selected and subject to double data extraction and quality assessment. The data extraction tables and quality assessment reports for papers subject to double data extraction and quality assessment were reviewed by a third reviewer (DJC), then discussed with the primary reviewers (GHR and RW). The level of agreement for data extraction was found to be good; there was also a satisfactory level of consistency in the quality assessment ratings for these papers.

\section{Quality assessment}

The National Institute for Health and Care Excellence qualitative appraisal guidance was used to assess methodological quality [17]. Studies were evaluated using a 14-item quality assessment checklist (Table 3). Reviewers endorsed the presence or absence of domain characteristics as clear, unclear or not reported. The checklist assessment of study quality can be marked: $(++)$ the majority of the criteria have been fulfilled; $(+)$ some of the criteria have been fulfilled; or (-) very few of the criteria have been met. Differences in quality assessment ratings between the reviewers were discussed until consensus was reached. Quality was assessed for descriptive purposes; papers were not excluded on the basis of the quality assessment; we drew upon relevant data from all included studies.

\section{Data synthesis}

A thematic synthesis approach was used [18]. Data from primary studies were used to initially develop descriptive themes that closely reflected study findings. Analytical themes were then formulated that go beyond the data and generate new interpretations of the results [18]; this involved three main stages:

1. Key findings, including the title of themes, from each article, specific to the review aims, were coded by GHR and RW using NVivo 10 [19].

2. Codes were organised to identify relationships, similarities and differences between the data. This stage identified key descriptive themes and subthemes.
3. Analytical themes were developed. This was an iterative and cyclical process. Reviewers explored the descriptive themes to generate novel findings based on the amalgamated data with the view of helping to inform future intervention development, policy and practice towards sedentary behaviour.

In this review, " represent authors' quotations whereas "” are used for participants' own words.

\section{Results}

\section{Literature search}

From 25,170 titles and abstracts identified (Fig. 1), 25, 020 were excluded. Full texts of 150 papers were assessed for eligibility; 44 were found to be eligible; reasons for exclusions are stated in Fig. 1. The 44 eligible studies fell into two categories; studies of the experiences of individuals outside of the workplace $(n=30)$, including, the experiences of those with a medical condition and those who had participated in programmes to reduce sedentary behaviour and, studies focused on sedentary behaviour in the workplace $(n=14)$. As previously stated, we made a post-hoc decision to remove studies that specifically examined workplace associated sedentary behaviour. Included studies are listed in Table 2. See Fig. 1 for PRISMA diagram and Additional file 2 for the references for the 14 workplace studies.

\section{Study characteristics}

Studies were published between 1995 [20] and 2017 [21-28]; 25 were published between 2008 and 2017 (Table 2). All but two studies [29, 30] examined the perceptions, experiences and sedentary behaviours of individuals living in Western countries. Whilst contemporary definitions differentiate between sedentary behaviour and physical activity [9], in the papers included in the review, thirteen focused specifically on sedentary behaviour and seventeen considered sedentary behaviour experiences, perceptions or reduction of sedentary behaviour in the context of physical activity participation.

Eleven studies examined experiences and/or perceptions of sedentary behaviour in older adults (typically $\geq 60$ years) [20, 22, 25, 26, 28, 29, 31-35]; ten studies focused on sedentary behaviour in people diagnosed with a medical condition [21, 23, 24, 36-42], four explored the perceived impact of socio-economic status on sedentary behaviour [43-46], two examined university students' experiences of sedentary behaviour [27, 47], two focused on working-age adults [30, 48], and one focused on cultural influences on sedentary behaviour [49]. The views of 918 individuals from ten countries are represented. Participants' ages ranged from 18 to 92 years. Sample size ranged from 9 [31] to 90 [29]. In 20 studies, 


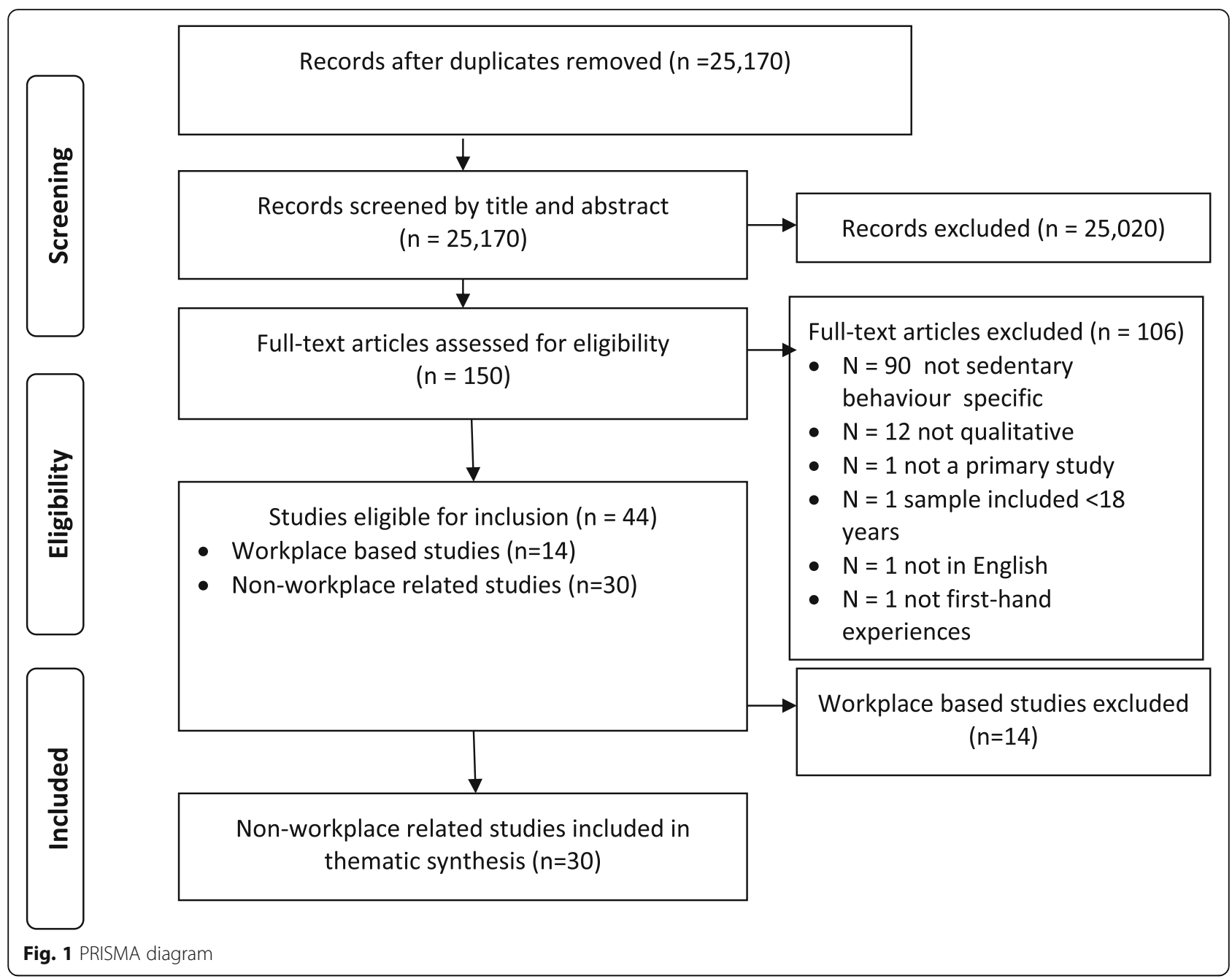

the sample was predominantly female or only recruited females, two studies investigated men only, and the remaining eight studies explored experiences of both men and women.

Overall, 22 studies examined adult's experiences and perceptions of sedentary behaviour, and eight studies investigated participant's experiences of engaging in interventions designed to reduce sedentary behaviour. The intervention studies included older adults [22, 25, 28, 34], overweight women [37, 42], women living in disadvantaged neighbourhoods [45] or adults at risk of type 2 diabetes [21].

\section{Quality assessment}

Most studies were graded highly across the fourteen quality domains (Table 3). Twenty-one (70\%) papers were graded ++ (good). Six papers were graded + (moderate); in these papers description of data generation and analysis was limited; in five [21, 22, 34, $38,43]$ the role of researcher(s) was not described in sufficient detail, and ways in which the relationship between participants and researcher(s) may have influenced the study were not considered. Three papers were rated as - (low). These papers did not clearly report how data were generated, nor the stages of or who was involved in the analysis. These papers did not discuss research limitations and were evaluated as being narrow in their conclusions.

\section{Thematic synthesis}

In total, 354 raw codes were recorded, from which ten descriptive themes emerged. After further analysis, three analytical themes were identified focusing on (i) the impact of different life stages on sedentary behaviour, (ii) lifestyle factors influencing sedentary behaviour, and (iii) barriers and facilitators to changing sedentary behaviour (Fig. 2).

Theme 1: the impact of different life stages on sedentary behaviour

Childhood

Some participants perceived their attitudes and behaviour related to their current sedentary behaviours 
Table 2 Summary of included studies

\begin{tabular}{|c|c|c|c|c|c|c|c|}
\hline $\begin{array}{l}\text { Primary author } \\
\text { and country }\end{array}$ & Year & Abbreviated aim(s) of study & $\begin{array}{l}\mathrm{N} \text { and } \\
\text { sampling } \\
\text { method }\end{array}$ & $\begin{array}{l}\text { Defining } \\
\text { participant } \\
\text { characteristics } \\
\text { (population, } \\
\text { gender and age) }\end{array}$ & $\begin{array}{l}\text { Data collection and } \\
\text { analysis }\end{array}$ & $\begin{array}{l}\text { Investigating } \\
\text { SB } \\
\text { intervention }\end{array}$ & $\begin{array}{l}\text { Quality } \\
\text { Appraisal }\end{array}$ \\
\hline $\begin{array}{l}\text { Adams, Gill } \\
\text { [37] } \\
\text { USA }\end{array}$ & 2015 & $\begin{array}{l}\text { To investigate feasibility of an } \\
\text { intervention aimed at reducing SB in } \\
\text { overweight women. }\end{array}$ & 64 Volunteers & $\begin{array}{l}\text { Overweight } \\
\text { women (BMl > 25) } \\
100 \% \text { female } \\
\text { Mostly aged > 50 } \\
\text { yrs. }\end{array}$ & $\begin{array}{l}\text { Open ended } \\
\text { questionnaire } \\
\text { Inductive analysis }\end{array}$ & $\sqrt{ }$ & + \\
\hline $\begin{array}{l}\text { Ball, Salmon, } \\
\text { Giles-corti [43] } \\
\text { Australia }\end{array}$ & 2006 & $\begin{array}{l}\text { To investigate perceived intrapersonal, } \\
\text { social and physical environmental } \\
\text { influences on PA of women of different } \\
\text { SES backgrounds. }\end{array}$ & 56 Snowball & $\begin{array}{l}\text { Healthy adults: } 19 \\
\text { high-SES, } 19 \text { mid- } \\
\text { SES and } 18 \text { low- } \\
\text { SES } \\
\text { 100\% female } \\
\text { Age range 18-65 } \\
\text { yrs. }\end{array}$ & $\begin{array}{l}\text { Semi-structured } \\
\text { interview } \\
\text { Thematic analysis }\end{array}$ & & + \\
\hline $\begin{array}{l}\text { Biddle, } \\
\text { Edwardson, } \\
\text { Gorely [21] UK }\end{array}$ & 2017 & $\begin{array}{l}\text { To explore experiences of a workshop } \\
\text { to understand outcomes of an } \\
\text { intervention aimed at reducing SB in } \\
\text { those at risk of type } 2 \text { diabetes. }\end{array}$ & $\begin{array}{l}71 \text { Purposive } \\
\text { (but unclear) }\end{array}$ & $\begin{array}{l}\text { Adults at risk of } \\
\text { type } 2 \text { diabetes } \\
\text { Data not present } \\
\text { for } n=71 \\
\text { participants } \\
\text { included in } \\
\text { qualitative study }\end{array}$ & $\begin{array}{l}\text { Evaluation sheets, } \\
\text { progress phone calls, } \\
\text { and telephone } \\
\text { interview } \\
\text { Inductive analysis }\end{array}$ & $\sqrt{ }$ & - \\
\hline $\begin{array}{l}\text { Britten, } \\
\text { Addington, } \\
\text { Astill [22] UK }\end{array}$ & 2017 & $\begin{array}{l}\text { To document participant's views and } \\
\text { effects of a dance programme. }\end{array}$ & $\begin{array}{l}22 \text { (but } \\
\text { unclear) } \\
\text { Purposive }\end{array}$ & $\begin{array}{l}\text { Community } \\
\text { dwelling older } \\
\text { adults } \\
95 \% \text { female } \\
\text { Mean age } 75 \text { yrs }\end{array}$ & $\begin{array}{l}\text { Three focus groups } \\
\text { Thematic content } \\
\text { analysis }\end{array}$ & $\sqrt{ }$ & + \\
\hline $\begin{array}{l}\text { Chastin, } \\
\text { Fitzpatrick, } \\
\text { Andrews [31] } \\
\text { UK }\end{array}$ & 2014 & $\begin{array}{l}\text { To investigate the determinants of SB } \\
\text { in older adults. }\end{array}$ & $\begin{array}{l}9 \\
\text { Convenience }\end{array}$ & $\begin{array}{l}\text { Older women } \\
100 \% \text { female } \\
\text { Age range } 70-92 \\
\text { yrs }\end{array}$ & $\begin{array}{l}\text { Semi-structured } \\
\text { interview } \\
\text { Framework analysis } \\
\text { /thematic analysis } \\
\text { approach }\end{array}$ & & ++ \\
\hline $\begin{array}{l}\text { Chen [29] } \\
\text { Taiwan }\end{array}$ & 2010 & $\begin{array}{l}\text { To explore barriers that older adults } \\
\text { experience in PA participation. }\end{array}$ & 90 Purposive & $\begin{array}{l}\text { Older adults } \\
\text { residing in long- } \\
\text { term care } \\
66 \% \text { female } \\
\text { Age range } 65-90 \\
\text { yrs. }\end{array}$ & $\begin{array}{l}\text { Interview } \\
\text { Content analysis }\end{array}$ & & ++ \\
\hline $\begin{array}{l}\text { Cousins, } \\
\text { Keating [20] } \\
\text { Canada }\end{array}$ & 1995 & $\begin{array}{l}\text { To identify factors to better } \\
\text { understanding of life pathways leading } \\
\text { women to PA or inactivity. }\end{array}$ & $\begin{array}{l}13 \\
\text { Theoretical }\end{array}$ & $\begin{array}{l}\text { Older women } \\
100 \% \text { female } \\
\text { Age over } 60 \text { yrs }\end{array}$ & $\begin{array}{l}\text { Two focus groups } \\
\text { consisting of active } \\
\text { or inactive women } \\
\text { Content analysis }\end{array}$ & & - \\
\hline $\begin{array}{l}\text { Curry, Duda, } \\
\text { Thompson [49] } \\
\text { UK }\end{array}$ & 2015 & $\begin{array}{l}\text { To compare perceived PA and ST to } \\
\text { objective data, and explore experiences } \\
\text { of PA- and ST amongst South Asian } \\
\text { women in the UK. }\end{array}$ & 24 Purposive & $\begin{array}{l}\text { South Asian } \\
\text { women - 92\% } \\
\text { were either obese } \\
\text { or overweight } \\
100 \% \text { female } \\
\text { Age range } 36-67 \\
\text { yrs }\end{array}$ & $\begin{array}{l}\text { Semi-structured } \\
\text { interview } \\
\text { Deductive content } \\
\text { analysis }\end{array}$ & & ++ \\
\hline $\begin{array}{l}\text { Damush, Plue, } \\
\text { Bakas [41] USA }\end{array}$ & 2007 & $\begin{array}{l}\text { To elicit barriers and facilitators of } \\
\text { exercise after stroke to inform the } \\
\text { development of post-stroke } \\
\text { programme. }\end{array}$ & $\begin{array}{l}13 \\
\text { Convenience } \\
\text { (but unclear) }\end{array}$ & $\begin{array}{l}\text { Stroke survivors } \\
38 \% \text { female } \\
\text { Mean age } 59 \text { yrs }\end{array}$ & $\begin{array}{l}\text { Three focus groups } \\
\text { Iterative consensus } \\
\text { process }\end{array}$ & & ++ \\
\hline $\begin{array}{l}\text { Deliens, } \\
\text { Deforche, } \\
\text { Bourdeaudhuij } \\
\text { [47] Belgium }\end{array}$ & 2015 & $\begin{array}{l}\text { To identify determinants of and } \\
\text { recommendations towards PA and SB } \\
\text { in Belgian university students. }\end{array}$ & 46 Snowball & $\begin{array}{l}\text { University } \\
\text { students } \\
63 \% \text { female } \\
\text { Mean age } 21 \text { yrs. }\end{array}$ & $\begin{array}{l}\text { Seven focus groups } \\
\text { Inductive thematic } \\
\text { approach }\end{array}$ & & ++ \\
\hline $\begin{array}{l}\text { Emadian, } \\
\text { Thompson [23] } \\
\text { UK }\end{array}$ & 2017 & $\begin{array}{l}\text { To explore factors influencing PA and } \\
\text { ST in overweight or obese South Asian } \\
\text { men living in the UK. }\end{array}$ & 31 Purposive & $\begin{array}{l}\text { Overweight or } \\
\text { obese South Asian } \\
\text { men } \\
100 \% \text { Male } \\
\text { Mean age } 44 \text { yrs }\end{array}$ & $\begin{array}{l}\text { Semi-structured } \\
\text { interview } \\
\text { Content analysis }\end{array}$ & & ++ \\
\hline
\end{tabular}


Table 2 Summary of included studies (Continued)

Primary author Year Abbreviated aim(s) of study and country

$\mathrm{N}$ and

sampling

method

Defining Data collection and

participant analysis

characteristics

(population,

gender and age)

Ezeugwu,

Garga, Manns

[24] Canad

Grossman,

Stewart [33]

USA

\author{
2003 To explore perceptions, motivations \\ and barriers of PA in underactive \\ community dwelling older adults. \\ 2017 To investigate perceptions of SB in \\ ambulatory stroke survivors.
}

13 Purposive
33
Convenience

Stroke survivor,

$46 \%$ female

Age range $26-75$

Older adults

$54 \%$ female

Mean age 80 yrs.
Greenwood-

Hickman, Renz,

Rosenberg [42]

USA

Guell. Shefer,

Griffin [32] UK

Keegan,

Middleton,

Henderson

[48] UK

Kolt, Paterson

and Cheung

[35] New

Zealand

Leask,

Sandlund,

Skelton [25] UK

Mabry, Al-

Busaidi, Reeves

[30] Oman

Martinez-

Ramos, Martin-

Borras, Trujillo

[38] Spain

Matei, Thune-

Boyle, Hamer

[34] UK

McEwan, Tam-

Seto, Dogra

[26] Belgium

Paxton,

Anderson,

Sakar [39] USA
2016 To explore motivators, barriers, and impact of SB reduction among a group of overweight older adults.$$
\text { overweight older aduls. }
$$

2016 To investigate how active living relates to later life experiences, aspirations and strategies of healthy ageing.

2016 To identify which socio-environmental factors motivate PA and/or SB, in adults.

2006 Identify the barriers to PA participation in sedentary older Tongan adults.

2017 Co-create a tailored public health intervention to reduce SB in older adults.

2013 To identify policy and programme options to address physical inactivity and prolonged sitting in Omani adults.

2015 To examine the opinions of overweight, 23 sedentary patients on ways to reduce this behaviour, their willingness to change, and prospect of receiving help.

2015 To explore participant's views towards an intervention to reduce ST and increase activity in older adults.

2017 To better understand the perceptions of older adults towards SB.

2016 To identify beliefs, perceptions, and recurrent themes associated with breaking up prolonged periods of sitting.

Shuval, Hebert, 2013 To explore impediments and enablers Siddiqi [44] USA to PA and investigate attitudes toward SB.

\section{4}

Convenience

\section{Overweight or Semi-structured}

obese older adults telephone interview

$67 \%$ female Inductive thematic

Age range 60-84 approach

yrs.

27 Purposive Older adults

$44 \%$ female

Age range 65-80

Semi-structured

interviews and

observations

Thematic analysis

15 Stratified

Working-age

adults

$53 \%$ female

Age range 31-59

Semi-structured

interview

Inductive content

24 Snowball

Tongan adults

$50 \%$ female

Age range 60-79

yrs.

11 Volunteers Older adults

$55 \%$ female

Age range 66-82

yrs.

analysis

Focus groups

Descriptive

qualitative

methodology

Ten interactive co-

creation workshops

Qualitative content

analysis

10 Purposive Public health

managers

$50 \%$ female

Semi-structured

interview

Thematic content

analysis and a

framework approach

Overweight or Five group and five

obese adults semi-structured

$65 \%$ female

Age range 25-63

yrs.

interviews

Thematic content

analysis

35 (but Older adults Semi-structured

unclear) Aged between 60 interview

Purposive and 75

26 Volunteers Older adults

$77 \%$ female

Age mean 74 yrs.

Thematic analysis

Four focus groups

and field notes

Breast cancer

31

Content analysis

Convenience/ survivors,

Purposive $\quad 100 \%$ female

(but unclear) Age range 22- 75

yrs.

25 Purposive Low income and

ethnic minority

adults

Semi-structured

telephone interview

Content data analysis

Semi-structured

interview

$52 \%$ female

Age range 30-54

yrs.

Framework approach

Semi-structured
interview

Thematic analysis

Qualitative interview

Standard coding,

categorising,

indexing, and

integration

techniques

Investigating Quality

SB Appraisal

intervention

$++$

$+$

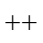

$++$

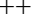


Table 2 Summary of included studies (Continued)

\begin{tabular}{|c|c|c|c|c|c|c|c|}
\hline $\begin{array}{l}\text { Primary author } \\
\text { and country }\end{array}$ & Year & Abbreviated aim(s) of study & $\begin{array}{l}N \text { and } \\
\text { sampling } \\
\text { method }\end{array}$ & $\begin{array}{l}\text { Defining } \\
\text { participant } \\
\text { characteristics } \\
\text { (population, } \\
\text { gender and age) }\end{array}$ & $\begin{array}{l}\text { Data collection and } \\
\text { analysis }\end{array}$ & $\begin{array}{l}\text { Investigating } \\
\text { SB } \\
\text { intervention }\end{array}$ & $\begin{array}{l}\text { Quality } \\
\text { Appraisal }\end{array}$ \\
\hline $\begin{array}{l}\text { Smetaniuk, } \\
\text { Johnson, } \\
\text { Creurer [27] } \\
\text { Canada }\end{array}$ & 2017 & $\begin{array}{l}\text { To examine students' perceptions of } \\
\text { factors that influence PA and SB. }\end{array}$ & $\begin{array}{l}43 \\
\text { Convenience }\end{array}$ & $\begin{array}{l}\text { Students in } \\
\text { Physical Therapy } \\
\text { Age range 22-33 } \\
\text { yrs }\end{array}$ & $\begin{array}{l}\text { Photovoice analysis - } \\
\text { document, four focus } \\
\text { groups } \\
\text { Thematic analysis }\end{array}$ & & + \\
\hline $\begin{array}{l}\text { Teychenne, } \\
\text { Ball, Salmon } \\
\text { [46] Australia }\end{array}$ & 2011 & $\begin{array}{l}\text { To explore influences on SB in women } \\
\text { living in socio-economically } \\
\text { disadvantaged neighbourhoods and } \\
\text { who are experiencing depressive } \\
\text { symptoms. }\end{array}$ & 18 Random & $\begin{array}{l}\text { Disadvantaged } \\
\text { women } \\
\text { experiencing } \\
\text { depressive } \\
\text { symptoms } \\
100 \% \text { female } \\
\text { Age range 18-46 } \\
\text { yrs }\end{array}$ & $\begin{array}{l}\text { Semi-structured } \\
\text { telephone interview } \\
\text { Thematic analysis }\end{array}$ & & ++ \\
\hline $\begin{array}{l}\text { Teychenne, } \\
\text { Ball, Salmon } \\
\text { [45] Australia }\end{array}$ & 2012 & $\begin{array}{l}\text { To investigate feasibility of two } \\
\text { intervention approaches (one print- } \\
\text { based and one web- based) designed } \\
\text { to promote PA and reduce SB amongst } \\
\text { women living in socio-economically } \\
\text { disadvantaged areas. }\end{array}$ & 42 Random & $\begin{array}{l}\text { Women living in } \\
\text { disadvantaged } \\
\text { neighbourhoods } \\
\text { and key } \\
\text { stakeholder } \\
100 \% \text { female } \\
\text { Mean age } 50 \text { yrs }\end{array}$ & $\begin{array}{l}\text { Questionnaire } \\
\text { Thematic analysis }\end{array}$ & $\sqrt{ }$ & ++ \\
\hline $\begin{array}{l}\text { Thomsen, } \\
\text { Beyer, Aadahl } \\
\text { [36] Denmark }\end{array}$ & 2015 & $\begin{array}{l}\text { To examine how patients with } \\
\text { rheumatoid arthritis describe their daily } \\
\text { SB. }\end{array}$ & $\begin{array}{l}15 \text { Purposive } \\
\text { (but not } \\
\text { stated) }\end{array}$ & $\begin{array}{l}\text { People living with } \\
\text { rheumatoid } \\
\text { arthritis } \\
66 \% \text { female } \\
\text { Age range } 23-73 \\
\text { yrs. }\end{array}$ & $\begin{array}{l}\text { Semi-structured } \\
\text { interview } \\
\text { Thematic analysis }\end{array}$ & & ++ \\
\hline $\begin{array}{l}\text { Trinh, Arbour- } \\
\text { Nicopoulos, } \\
\text { Sabiston [40] } \\
\text { Canada }\end{array}$ & 2015 & $\begin{array}{l}\text { To examine perceptions of } S B \text { and the } \\
\text { preferences for a SB intervention of } \\
\text { men on androgen-deprivation therapy. }\end{array}$ & $\begin{array}{l}27 \\
\text { Convenience } \\
\text { (but not } \\
\text { stated) }\end{array}$ & $\begin{array}{l}\text { Prostate cancer } \\
\text { survivors } \\
\text { 100\% Male } \\
\text { Age mean } 74 \text { yrs. }\end{array}$ & $\begin{array}{l}\text { Nine focus groups } \\
\text { Thematic analysis }\end{array}$ & & ++ \\
\hline $\begin{array}{l}\text { Van Dyck, } \\
\text { Mertens, } \\
\text { Cardon [28] } \\
\text { Belgium }\end{array}$ & 2017 & $\begin{array}{l}\text { To examine determinants of } \mathrm{PA} \text { and } \mathrm{SB} \\
\text { and needs regarding PA intervention in } \\
\text { recently retired adults. }\end{array}$ & $\begin{array}{l}37 \\
\text { Convenience }\end{array}$ & $\begin{array}{l}\text { Recently retired } \\
\text { adults } \\
51 \% \text { female } \\
\text { Mean age } 63 \mathrm{yrs} .\end{array}$ & $\begin{array}{l}\text { Four focus groups } \\
\text { Thematic analysis }\end{array}$ & $\sqrt{ }$ & ++ \\
\hline
\end{tabular}

Definition of terms in Table 2: SB Sedentary Behaviour, BMI Body Mass Index, PA Physical Activity, ST Sedentary Time, $n$ Number, SES Socio-Economic Status, UK United Kingdom, USA United States of America, yrs. Years

were established in childhood. Individuals explained how social and physical environments in which they grew up in influenced their levels of sedentariness $[38,46]$. Parenting style as a determinant of sedentary behaviour was also described. In one study published in 1995 interviewing older women, one 'inactive woman' [defined as someone who did not exercise 'regularly'] reported that her mother would at times tell her she was "overdoing it" and she had "better sit down and read a book or do a bit of sewing". While this reflects a single perspective on the influence of parental attitudes toward activity in a different time period, it highlights the perceived importance of parental influences on shaping later life attitudes toward sedentary behaviour [20].

Other factors impacting levels of sedentary behaviour at this stage were family norms, social pressures, and the interests and capabilities of the participant [20]. For example, a 'turning point' in later childhood was described; individuals would compare, for example, their performance or competency in sport to that of their peers. This comparison led some to focus their efforts on less active pursuits: "If you are not good at organised sport you are not going to continue it". Such turning points could shape later life decisions to engage in pursuits which gave pleasure, such as knitting, needlework and watching television, but which were nonetheless sedentary. [20]. However, attitudes toward sedentary behaviour formed at this stage were not immutable and could be subject to change as a result of later life experiences. In more recent studies, one participant explained that after leaving home her level of sedentary behaviour remained the same as that imposed in the family home [46], while in contrast, another interviewee explained that he was now free to engage in as much sedentary behaviour as he wanted [47]. 
Table 3 Methodological quality of studies (numbers refer to the number of studies $n=30$ )

\begin{tabular}{|c|c|c|}
\hline Domain & Rating & \\
\hline \multirow[t]{2}{*}{ Theoretical rationale: appropriateness } & Appropriate & Inappropriate/ Not sure \\
\hline & 29 & 1 \\
\hline \multirow[t]{2}{*}{ Theoretical rationale: clarity } & Clear & Unclear / Mixed \\
\hline & 29 & 1 \\
\hline \multirow[t]{2}{*}{ Study design } & Defensible & Indefensible / Not sure \\
\hline & 28 & 2 \\
\hline \multirow[t]{2}{*}{ Data collection } & Appropriately & Inappropriately / Not sure \\
\hline & 22 & 8 \\
\hline \multirow[t]{2}{*}{ Trustworthiness: role of researcher } & Clear & Unclear / Not described \\
\hline & 18 & 12 \\
\hline \multirow[t]{2}{*}{ Trustworthiness: clarity } & Clear & Unclear / Not sure \\
\hline & 21 & 9 \\
\hline \multirow[t]{2}{*}{ Trustworthiness: reliability } & Reliable & Unreliable / Not sure \\
\hline & 24 & 6 \\
\hline \multirow[t]{2}{*}{ Analysis: rigorous } & Rigorous & Not rigorous / Not sure \\
\hline & 22 & 8 \\
\hline \multirow[t]{2}{*}{ Analysis: richness } & Rich & Poor / Not sure \\
\hline & 25 & 5 \\
\hline \multirow[t]{2}{*}{ Analysis: reliability } & Reliable & Unreliable / Not sure \\
\hline & 22 & 8 \\
\hline \multirow[t]{2}{*}{ Analysis: convincing } & Convincing & Not convincing/ Not sure \\
\hline & 28 & 2 \\
\hline \multirow[t]{2}{*}{ Analysis: relevance } & Relevant & Irrelevant / Partially relevant \\
\hline & 29 & 1 \\
\hline \multirow[t]{2}{*}{ Conclusions } & Adequate & Inadequate / Not sure \\
\hline & 24 & 6 \\
\hline \multirow[t]{2}{*}{ Ethics } & Appropriate & Inappropriate / Not sure \\
\hline & 29 & 1 \\
\hline
\end{tabular}

To achieve the highest grade (++) consensus between reviewers was required

\section{Student and adulthood}

Naturally, social and family roles, employment and economic circumstances changed over time in adulthood. Such factors were reported as directly influencing time spent sedentary, the consequences of which, could act as facilitators or barriers to reducing sedentary time. In the two studies focused on university student experiences, students reported engaging in high levels of sedentary behaviour. They identified that academic pressures and university culture required long periods of sitting. The sedentary tendency promoted in academic settings seemed to encroach on other areas of life as participants "become used to living like that" [38]. Healthy life choices were described as being "sacrificed" over gaining an education. For some, this appeared to be a source of conflict as the behaviour was inconsistent with their knowledge of a healthy lifestyle [27, 47].
Sedentary behaviour associated with employment and the influence of employment on daily life emerged as an important determinant of sedentariness. Employment (or lack of [41]) was described as "directly" influencing levels of sedentary behaviour [48]. This was evident across a range of different participant groups. Factors that increased sedentary behaviour included: commuting to work; inconsistent or long working hours meaning people found it difficult to be active; having to sit at a desk; attend meetings [37]; or due to the effects associated with work, including stress and fatigue [38, 43, 48, 49]. In contrast, participants in a study of stroke survivors explained that, after resigning from employment due to their health, they used exercise to fill their empty daily schedules [41].

In adulthood, family roles or "obligations" [38] such as increased responsibilities around the home, relationships or being a parent appeared to be a 


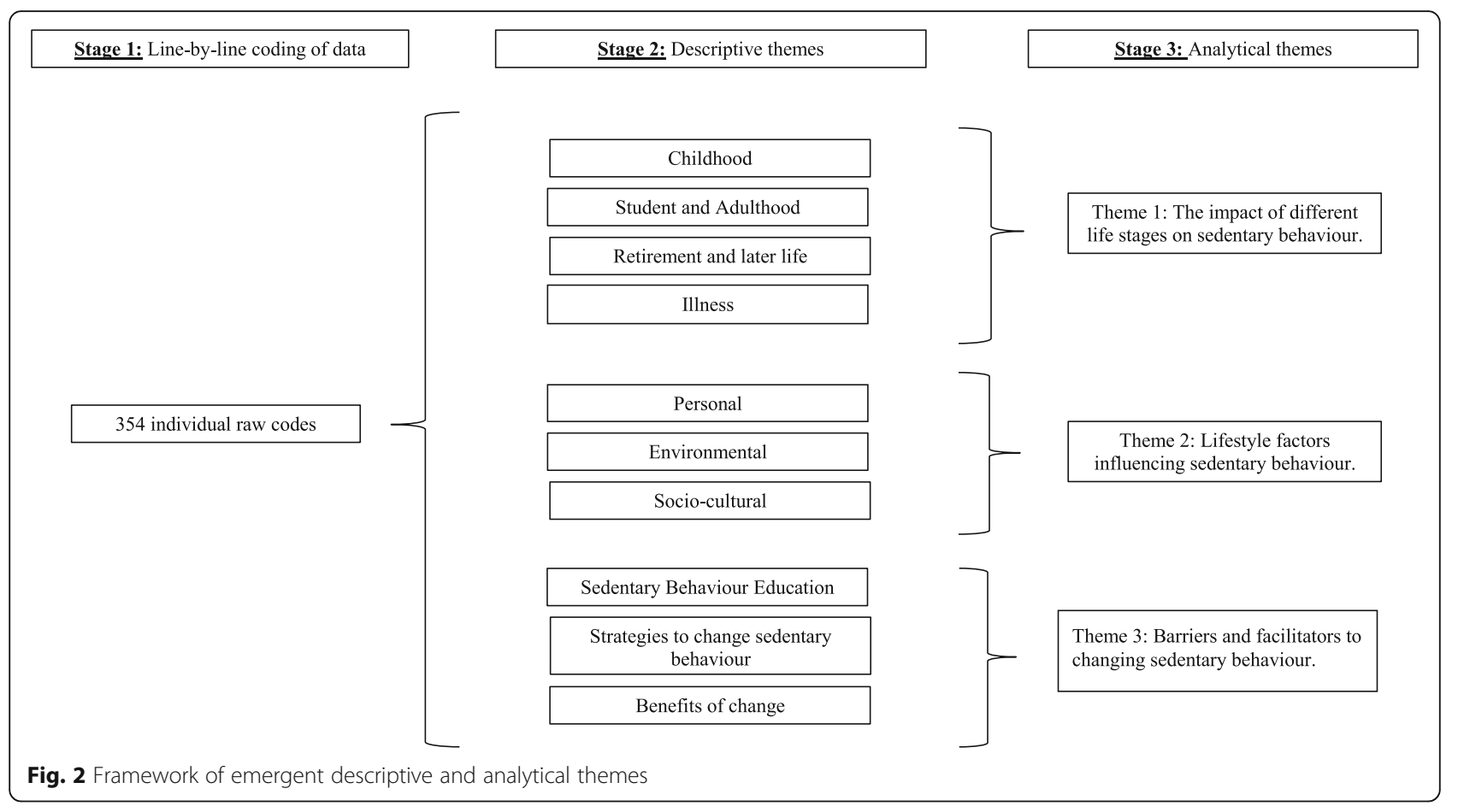

common factor that affected levels of sedentariness: "you get tied up with the social engagement of your family" [30]. These pressures were also reflected in experiences of sedentary behaviour interventions as family and work commitments were a common barrier to compliance $[37,42]$. While physical and time demands associated with children generally limited parents' opportunities to engage in physical activity, for some, responsibilities for children meant that they did not have the free time to be sedentary. Indeed, some described children as 'energetic resources' $[20,44,48]$.

\section{Retirement and later life}

Older participants, in the later stages of life, described a general slowing down and becoming more sedentary as a result of internal (i.e. interests, routines and ageing) and external (i.e. expectations, social norms) pressures. The hobbies and leisure activities that older adults took part in were predominately sedentary e.g. passive television (TV) viewing [25, 28], reading, sewing [38], and knitting [26]. It seemed that while older adults acknowledged the negative consequences related to their sedentary activities, such concerns were displaced if the behaviours were enjoyable, and associated with cognitive or social benefits: 'Many of the participants described how their preferred sedentary behaviour provided them opportunities to meet new people' [22].

Stigmatising aspects of participants' social identities also emerged and cohered around the view that older adults can be viewed by others as 'tired, sick, lonely, or depressed' [26], and that they should 'sit all day'. While it was not explicitly reported, this view appeared to be held by society, friends and family (as well as some older adults themselves). Older adults interviewed in one study reported feeling 'typecast' as "not useful" or "unable" and that sitting should be their 'main mode of living' [31]. Despite these perceived pressures, some participants endeavoured to stay physically active, and harboured what was described as an 'active ageing attitude' [32]. Notwithstanding this however, older adults' experiences and perceptions of limitations in relation to their ageing bodies appeared highly salient: "I use to do a lot more things but now... you just can't do it" [26, 29]. For some, an increase in sedentary behaviour was motivated by their concerns that 'standing up more would interfere with the strategies they had put in place, in response to their declining health or mobility [31] (see 3.5.4).

There were mixed views about the health benefits of reducing sedentary behaviour and maintaining a physically active lifestyle. A widely held belief that older adults should 'rest' [31] was reported, and whilst encouraging rest may be perceived as a 'caring gesture' by family or friends, participants pointed out that this behaviour 'took opportunities for being active and independence away from them' [31]. On the other hand, some studies highlighted how family members positively influenced and supported older adults to reduce time spent sedentary through the shared responsibility of looking after grandchildren $[48,49]$. 


\section{IIIness}

It was commonly reported that the impact of poor health contributed to prolonged periods of sedentary behaviour. Participants explained that symptoms associated with health status, such as 'fatigue' and 'pain' increased sedentary behaviour [24, 36, 39]. Interestingly however, pain and stiffness were also reported as reasons for breaking up periods of sedentary behaviour and increasing activity levels [40-42]. This bi-directional relationship between sedentary behaviour and illness was further exemplified when participants described sedentariness and mental health [31, 38]. Depression was commonly linked to use of sedentary behaviour $[24,31]$ with some explaining that: 'overcoming depression is essential to reducing sedentary behaviour' [24], that they became more active 'to fight depression' [31], or sedentary behaviour was used to 'switch off' and 'remove themselves from their depressive frame of mind' [46].

Engaging in sedentary behaviour was a common strategy used by participants to prevent declining health or further injury, and transitioning back into illness. Sedentary behaviour was adopted by some as a means to recover from and manage chronic disease symptoms [24, 31] and rest was viewed as an important element in the recovery process [24], suggesting that sedentary behaviour was used as a precautionary or protective behaviour. There was also evidence to suggest that caring for and looking after family or friends who lived with a health problem reduced levels of activity and increased sedentary time [31, 36, 38, 48]: "My wife has a serious lung disease. We are very limited in doing things ... Before, we always went out to concerts" [36].

\section{Theme 2: lifestyle factors influencing sedentary behaviour Individual}

The range of sedentary behaviours individuals reported engaging in were considerable and included: reading, watching TV, crosswords, meditation, knitting, bingo, eating, gaming, studying, religious functions, motorised transport and 'simply lying down' [24]. Participants' interests (or at least their levels of activity and sedentary behaviour [30]) seemed to be influenced by age, gender [48], physical mobility, culture [49] and socio-economic status [43]. One interviewee reported that the sedentary activities engaged in 'were an important part of their life and self-image' [42] and to change this would not only be difficult, but it would change who they are as a person. Participants in two studies reported engaging in sedentary behaviour because it was "comfortable" and "relaxing" [24, 38]. Indeed, this was described as a potential barrier as people were concerned that breaking up sedentary behaviour would 'ruin' their enjoyment. In line with the pleasurable attributes of sedentary behaviour, individuals described using it as a reward [42].
Given this level of enjoyment, certain sedentary activities appeared to be a 'compulsion' as some participants described needing 'self-discipline' [47] or having to make a 'conscious effort' [24] to be less sedentary.

People reported engaging in sedentary behaviour for specific activities, such as reading or using the computer. This was due to the associative benefits, for example, when engaged in sitting individuals reported that they could give greater attention to the task at hand [25]. Sedentary behaviour however was not always associated with interests, need or comfort as it was also attributed to people being 'lazy', using it to 'pass the time' [46] or their disinterest in more active pursuits [31, 36]. As such, sedentary behaviour appeared to be an "easy", [32, 42] cheap or habitual alternative [47] to more active behaviours. Some forms of sedentary behaviour were seen as being integral components to daily life [25], for instance, across studies it was common for participants to sit down to rest after work [31, 38, 48, 49]. However, participants involved in focus groups investigating their experiences of a sedentary behaviour intervention explained that, reducing sitting time at home or in the evenings would be easier than limiting sitting at work [21].

There were a number of facilitators towards individuals being more active (and reducing sedentary behaviour). These included: being 'motivated and determined' to be less sedentary [24, 48]; adhering to physical activity guidelines; motivated to age well [32]; to keep their independence [33]; and to look good and be healthy.

\section{Environmental}

Individuals' physical environment was an important factor when understanding the determinants of sedentary behaviour. People described being more likely to be sedentary during the winter months, when it was cold or wet, and short daylight hours [23, 24, 26, 31, 38, 40, 45, 46]. In line with this, symptoms associated with illnesses or ageing were barriers, for example, people with impaired eyesight expressed concerns over obstacles i.e. shrubs, which posed as hazards [33].

Other practical constraints influencing sedentariness were financial costs [22], poor transport links making walking to certain places difficult; home location [48], work-life balance and neighbourhood crime. Problems associated with childcare [46], and lack of availability of gyms, parks or greenspace, and poor quality of services [21, 44, 46] were also reported. Similar restrictions were described as logistical barriers by participants in sedentary behaviour interventions [22]. There was evidence to suggest that some individuals externalised fault, blaming practical factors for being less sedentary; when students were asked how they could reduce their 
sedentary behaviour, they predominately reported changes that others could make as opposed to actions that they could perform themselves [27, 47].

\section{Socio-cultural}

Family, friends and pets [27, 32, 38, 41] were described as being able to prompt, remind and motivate participants to decrease their sitting time and engage in more physically active pursuits [42, 46, 48]: "He [a friend] lost three stone in a year...And it suddenly clicked and I decided I wasn't a lost cause" [48]. However, they could also discourage participants: one interviewee explained that if she went out on a Saturday with her mother she would "go on foot", whereas if she went out with her father they would go by car as he "doesn't want to walk" [38]. The benefits of social support were also described by participants in sedentary behaviour interventions, such as meeting new people, or feeling that they must attend sessions as to not let others down [22]. Although the current review included only two studies examining sedentary behaviour outside of Western culture, different socio-cultural norms and family traditions were shown to influence sedentary behaviour [42]. For example, in one study examining sedentary behaviour in South Asian women living in the United Kingdom (UK), the culturally accepted norm when becoming a motherin-law was being 'entitled to do a great deal of sitting after having raised a family' [49].

Notwithstanding a high proportion of the studies reviewed here examined a female dominant sample, a strong gendered dimension emerged [30, 43, 48]. Several participants made reference to the limited culturally appropriate options to be less sedentary available to women: "The ladies who have no job, what [option] will they have except sitting at home? They cannot just go around roaming between the houses, socially it's not acceptable" [30]. Differences in socio-economic status appeared in the value afforded to certain leisure-time sedentary behaviours. Women of all socio-economic groups reported preference for TV viewing, but this appeared particularly popular as a pastime among women of low socio-economic status and, to a lesser extent, mid socio-economic status [43, 46].

The media reportedly played an important role in influencing participants' perceptions of sedentariness. While it helped some individuals to live a healthier lifestyle, for others, it desensitised them or caused feelings of hopelessness as they felt there is little they could do about being sedentary $[26,48]$. The importance of how key messages around sedentary behaviour are delivered was further demonstrated in intervention studies, as participants explained some of the information provided came across as being patronising [42, 45].
Theme 3: barriers and facilitators to changing sedentary behaviour

Sedentary behaviour education

Many participants were unfamiliar with the term sedentary behaviour and were not aware of the associated health consequences [23-25, 28, 47, 49]. Further, misconceptions around sedentary behaviour were described: a stroke survivor showed surprise when told that lying down during non-sleeping hours was considered sedentary behaviour' [24]. Lack of knowledge contributed to cognitive distortions with some individuals demonstrating all-or-nothing thinking, perceiving that if they were not physically active they must be sedentary [21, 46, 47]. Other participants found it difficult to understand that their level of sedentary behaviour was problematic because they regularly engaged in physical activity [42]. Also, as discussed in Theme 1 (retirement and later life), there seemed to be cognitive dissonance around sedentary behaviour as while many viewed sedentariness negatively, they felt that the seated activities they engaged in were not negative because they perceived those behaviours had 'many social and cognitive benefits' [26]. Despite participants' limited knowledge of sedentary behaviour, it was apparent that, on some level, individuals did understand that living a sedentary lifestyle was unhealthy. For example, participants described the guilt they associated with being sedentary $[38,46]$, negative connotations and the stigma of identifying as being sedentary $[26,48]$; and some actively reduced their sedentary behaviour to be a good role model [46]. In one intervention study, participants described the link between too much sitting and health as logical, maybe even obvious...' [21].

Educating people about sedentary behaviour was a common suggestion made by participants and researchers to reduce sedentary time. Participants felt this could be achieved in schools, workplace settings, community centres, places of worship, and health and social care settings $[23,38]$. Although none of the studies included in this review explored the perceptions or experiences of healthcare professionals in relation to sedentary behaviour, healthcare providers reportedly played an important role in educating and influencing participants' sedentary behaviour. One interviewee explained [48, 49]: "I actually do stand a lot when I'm watching TV...I've been given advice by my GP [General Practitioner] to do it" [46].

\section{Strategies to change sedentary behaviour}

Different strategies were described to reduce the total amount and break up bouts of sedentary behaviour. In one study [21] participants were asked to list key strategies used to 'sit less or move more' during a sedentary behaviour intervention. Eighteen different methods were suggested; the most common being walking, standing during TV breaks, 
reducing or turning off the $\mathrm{TV}$, going to the gym, and standing while talking on the phone [21]. However, participants tended to focus more on strategies that specifically increased physical activity providing 'little to no specific recommendations' targeting sedentary behaviour [21, 46, 47] [46]. In intervention studies, there was a mixture of attitudes towards alternatives to sedentariness. Some participants were not in favour of modifying current sedentary behaviour, doubted the effectiveness of suggested strategies [21] or felt alternatives were too artificial or forced [42]. Others however, appeared to enjoy this version of 'multitasking' as it was a 'new way of exercising' [22]. Nevertheless, it was clear that any changes needed to be incorporated into participants' everyday lives and become habitual [34].

Participants in sedentary behaviour interventions described the use of different behaviour change techniques. These included: monitoring their own sedentary behaviour [42]; having the opportunity to problem solve and overcome barriers to being more active; reading leaflets or booklets that discuss the importance of physical activity and reducing sitting time [45]; and regular prompts and reminders, for instance, key messages such as sit less,' 'move more' and 'stand more' [21]). Financial incentives (e.g. reduced gym fees); opportunities for social comparisons and support [21]; being able to set their own sedentary reduction goals [25, 42]; praise from others [42]; and rewards for reducing sedentary behaviours [40] were also reported. Technology-related behaviour change techniques were discussed including, wearable devices and computer or smart-phone/tablet applications (apps). Such strategies were described as helping to track progress, 'enable, 'prompt' or 'remind' participants to sit less [21], as well as being a key resource for information. While many participants had something positive to report about these methods, problems were experienced - this typically consisted of devices not being user friendly or practical [21, 42].

For some people, their experience of the strategies designed to alter sedentary behaviour seemed to change as the intervention progressed. It was noted, for example, that some techniques could become rather agitating or frustrating and some individuals felt that failing to achieve intervention goals "could be depressing" [45]. Both substantial, long-term changes as well as more subtle, short-term nudges to reduce sedentary behaviour were suggested [21, 45]. It was identified that strategies to reduce sedentary behaviour had to be suitable, straightforward, achievable, enjoyable [35, 37], time efficient, and tailored to the individual's particular circumstance, ability, and personal characteristics (such as age or gender) [45]. Indeed, 'the suitability of the activities could either motivate physical activity or sedentariness' [48]; in one study, stroke survivors explained that if strategies were unsustainable or unrealistic, then they were 'needless' [24].

\section{Benefits of changing sedentary behaviour}

Through changing levels of sedentary time and activity, participants in sedentary behaviour intervention studies reported a range of benefits. This included: increased stamina; balance; weight loss [21]; general 'physical and psychological' wellbeing [22]; a more active and 'fulfilling' life; pride at having made a change [42]; improved mood; enhanced sleep quality [34]; cognitive benefits; quality of life and 'mental health'. Participants explained that they were motivated to change by the short-term achievements "...you're immediately rewarded when you stand up and you're not so stiff..." [42]) as well as the anticipated long-term gains [25, 42]: "Weight loss always motivates women" [45].

\section{Discussion}

This review aimed to synthesise current knowledge in regards to the experience and perception of sedentary behaviour and participation in interventions designed to reduce sedentary behaviour in adults. We synthesised data from 918 participants from 30 studies and identified three analytical themes: (i) the impact of different life stages on sedentary behaviour, (ii) lifestyle factors influencing sedentary behaviour and (iii) barriers and facilitators to changing sedentary behaviour.

The first theme reflected the micro and macro pressures experienced at different life stages that are influential in shaping individuals' beliefs, attitudes and behaviour related to sedentariness. The Capability, Opportunity, Motivation and Behaviour (COM-B) model [50] recognises that behaviour is part of an interacting system. The heterogeneous nature of the participant groups in the current review allowed us to trace how these different components may be shaped depending on life stage. In childhood, individuals described having the motivation and capability of being active; however, parental and academic influences could limit opportunities, sometimes promoting sitting time. In adulthood, all components were influenced by personal experiences, social and working commitments, and economic circumstances. Overall, in the studies reviewed, this meant that participation in exercise reduced and sedentariness typically increased between childhood and adulthood. In later life, declining health meant that individuals were not always capable of being active and cultural expectations reduced opportunities, promoting sedentariness, regardless of whether individuals were motivated to be less sedentary or not.

Participants in some studies described using sedentary behaviour to cope with changes in health status. 
Increased sedentary behaviour in illness has been reported elsewhere [51]. Notwithstanding that some sedentariness is necessary and inevitable in illness; our review highlights other important motivations behind this behaviour, suggesting it is also perpetuated by social and family norms, personal experiences and associated benefits, such as gratification. There is a risk however, that using sedentary time as a protective behaviour could become a self-fulfilling prophecy. For example, the belief that sedentary behaviour must be engaged in when ill, in addition to declining physical fitness caused by limited activity, may lead to further reduced mobility and impact negatively on health. Additionally, this behaviour may be generalised to cope with other demands associated with daily life.

Interventions designed to reduce sedentary behaviour should consider external and internal influences on individuals and groups at different life stages [52]. Individuals with (and without) medical conditions may need specific support to develop alternative coping techniques associated with less health risk.

The second theme demonstrated the multifaceted nature of sedentary behaviour. In our review, sedentary behaviour reportedly played a large role in participants' daily lives. However, the motives behind the adoption of this behaviour differed. When looking to change behaviour it is important to first formulate and understand the behaviour and approach the situation in a balanced way, recognising that not all sedentary behaviours/activities are inherently negative. Identifying personalised goals for sedentary behaviour reduction [53] will help guide what and how intensive behaviour change strategies need to be. This can incorporate understanding core beliefs associated with sedentary behaviours and identify alternatives to and adapt existing sedentary activities.

Environmental factors, in particular the weather, were commonly discussed as variables influencing sedentariness. The environmental barriers were similar to those reported in the literature on physical activity [54]. To reduce many of the practical barriers, sedentary behaviour reduction interventions could target where and when to change behaviour; while exercise is likely to be managed externally (away from the home), reducing sedentary behaviour can be achieved in the workplace or at home.

The third theme identified that while physical activity appears to be a widely understood term, the concept of sedentary behaviour and associated negative health consequences were less well known. Moreover, some participants dichotomised sedentariness and physical activity, believing that, if they are not physically active in line with guidelines they are sedentary, thus failing to recognise the value of light intensity physical activity as means to reduce sedentary behaviour. There is a need to educate people about the health risks of sedentary behaviour, as well as about methods and benefits of reducing sedentariness. However, Leask et al. pointed out that people are unlikely to be motivated to reduce their time spent sedentary if they are unaware or do not understand the impact of sedentary behaviour. Moreover, due to the importance and enjoyment of sedentary-based activities, 'demonising' all forms of sedentary behaviour is unlikely to be effective [25]. A sedentary behaviour reduction programme co-produced by older adult's highlighted the value of adequately and sensitively framing this kind of information. Group members suggested educational approaches should focus on the 'drawbacks' of sedentary behaviour as well as the positives of reducing sedentary behaviour and emphasise that some sedentary behaviours are 'beneficial', such as cognitively stimulating seated activities [25]. Making a distinction between active, purposeful and passive sedentary activities is likely to be beneficial; this categorisation is consistent with how some individuals conceptualise and justify their sedentary behaviour [55]. In addition, given that some participants recognised the negative effects of sedentary behaviour and yet were still sedentary, it is clear that knowledge alone is insufficient to bridge the gap between cognitions and behaviour or to bring about sustained change. Additional strategies are required that look to serve different functions. Education may be effective in managing beliefs about sedentary behaviour. However, other methods such as individually tailored goal setting and action planning are needed to change established behaviours. Strategies aimed at initiating change will not necessarily be sustainable and methods to maintain change are unlikely to be acceptable if initial strategies fail to motivate individuals. Although we have identified some of the motivators for reducing sedentary behaviour, we are unable to draw firm conclusions concerning which sedentary behaviour specific strategies could be implemented and for what populations. Our findings do however support the use of multiple techniques and intervention functions [50], and confirm that one single approach is unlikely to be suitable for all.

In highlighting the multifaceted nature of sedentary behaviour, our review findings are consistent with the elements of the social-ecological model [56] and also with the findings of a consensus study that developed a systembased framework consisting of six clusters of determinants of sedentary behaviour [57]. Sedentary behaviour in adults is influenced by a range of interrelated factors; public health interventions must take account of these factors. Strategies to reduce sedentary behaviours must be easily incorporated into participants' daily lives and be purposeful.

\section{Limitations}

We only included studies published in English and the majority of studies reviewed examined experiences of 
sedentary behaviour in Western countries. Therefore, the review findings cannot easily be generalised to other parts of the world. Exploring experiences of sedentary behaviour in a range of different cultures and populations would provide further insight into how socio-cultural, socio-economic and environmental factors shape peoples' attitudes and behaviours towards sedentariness.

There is no single, best approach to conduct a qualitative synthesis. Instead, the method used should be guided by the aims and purpose of the synthesis $[58,59]$. We used a thematic synthesis approach in this review; but we recognise that there is debate about whether it is appropriate to synthesis data generated in research using different qualitative methods. One limitation of qualitative synthesis such is that the meta-themes developed are often broad and overarching; the specific contexts in and about which participants speak are difficult to retain in this kind of synthesis.

An additional aim of the review and thematic synthesis was to explore the views of carers, relatives and health and social care professionals in relation to sedentary behaviour in adults. We did not find any articles investigating views of these groups in relation to sedentary behaviour. It is possible that relevant articles were missed because our search terms were not specific to carers, relatives and health and social care professionals. Research is needed to the explore role that carers, relatives and health and social care professionals play in influencing sedentariness and whether and how their roles can be optimised.

The initial search for this review was conducted at the end of September 2017. We acknowledge that this area of public health research is experiencing considerable growth in numbers of publications. Studies since the end of September 2017 were not included in the current synthesis. Recognising this limitation, we repeated the search using the same parameters in April 2019. Overall, 7273 unique articles were identified. Two reviewers completed title and abstract screening and identified 33 titles for full text screening; nine of these studies met our criteria. Five papers investigated sedentary behaviour in those with a medical condition [60-64], three explored factors affecting older adults' sedentary behaviours and the acceptability of potential strategies to reduce sedentary time [65-67] and one focused on factors influencing time spent in sedentary behaviour and explored strategies to reduce this sedentariness in African American women in home, work, and social environments [68]. This demonstrates the growing interest in understanding people's experiences of sedentary behaviour. Whilst the reported findings of these studies appear to be largely consistent with those we report following our thematic synthesis, the iterative nature of a thematic synthesis means that it would not have been appropriate to analyse and interpret these data in a post-hoc addition to our synthesis. What is more, qualitative research is less concerned with generalisability of findings, as it is with seeking situational, as opposed to demographic representativeness [69].

\section{Conclusions}

Sedentary behaviour is influenced by a complex interaction between individual, environmental, socio-economic and socio-cultural factors. Micro and macro pressures are experienced at different life stages, including childhood, adulthood, and later-life and in the context of long-term illness that shape individuals' beliefs and behaviour related to sedentariness. Our findings suggest that knowledge of sedentary behaviour and the associated health consequences is limited in adult populations. At a population level there is a need for a clear and understandable definition of sedentary behaviour. This should be associated with provision of accessible information about ways in which sedentary behaviour reduction might be integrated in peoples' daily lives. Interventions targeting a reduction in sedentary behaviour will need to consider the multiple influences on sedentariness when designing and implementing interventions.

\section{Additional files}

Additional file 1: Example search strategy (MEDLINE) (DOC $25 \mathrm{~kb}$ )

Additional file 2: Excluded workplace-based studies (DOC 56 kb)

\section{Abbreviations}

Apps: Applications; BMI: Body Mass Index; COM-B: Capability Opportunity, Motivation and Behaviour; GP: General Practitioner; N: Number; NIHR: National Institute for Health Research; PA: Physical Activity; PGfAR: Programme Grants for Applied Health Research; PRISMA: Preferred Reporting Items for Systematic Reviews and Meta-Analyses; SB: Sedentary Behaviour; SES: Socio-Economic Status; ST: Sedentary Time; TV: Television; UK: United Kingdom, USA United States of America; yrs: Years

\section{Acknowledgements}

The authors wish to thank Deirdre Andre for her advice regarding database searching and for her work in tracking down papers for including in the review. We thank Dr. Mark Perry for his contribution to development of the search strategy and review protocol development. We also thank Dr. Rekesh Corepal for his assistance in screening titles, abstracts and full texts identified in the updated April 2019 search.

\section{Authors' contributions}

GHR, RW, DJC, AF, CF, RL, GM, CE, AP and $I H$ were responsible for the conception and design of this review. GHR, RW and DJC designed and implemented the initial search strategy. GHR, RW and DJC completed full text screening and GHR and RW assessed the quality of the studies with oversight from DJC. GHR and RW extracted study data which was then reviewed by DJC. GHR drafted the paper with subsequent editing provided by DJC and RW. AF, CF, RL, GM, CE, AP and IH critically reviewed and revised the different versions of the manuscript. All authors read and approved the final manuscript.

\section{Funding}

National Institute for Health Research (NIHR) Programme Grant for Applied Research (PGfAR): RP-PG-0615-20019.

This paper presents independent research funded by the National Institute for Health Research under its Programme Grants for Applied Research Programme (Grant Reference Number RP-PG-0615-20019). The views 
expressed are those of the authors and not necessarily those of the National Health Service (NHS), the NIHR or the Department of Health.

\section{Availability of data and materials}

Not applicable.

\section{Ethics approval and consent to participate}

Not applicable.

\section{Consent for publication}

Not applicable.

\section{Competing interests}

The authors declare that they have no competing interests.

\section{Author details}

${ }^{1}$ Department of Clinical Psychology, University of Sheffield, Sheffield, UK. ${ }^{2}$ Academic Unit of Elderly Care and Rehabilitation, Leeds Institute of Health Sciences, Temple Bank House, University of Leeds, Bradford Royal Infirmary, Bradford BD9 6RJ, UK. ${ }^{3}$ School of Health Sciences and Priority Research Centre for Stroke and Brain Injury, University of Newcastle, Newcastle, Australia. ${ }^{4}$ Leeds Institute of Clinical Trials Research, University of Leeds, Leeds, UK. ${ }^{5}$ Physical Activity for Health Research Centre, University of Edinburgh, Edinburgh, UK. ${ }^{6}$ School of Psychology, University of Leeds, Leeds, UK. ${ }^{7}$ Geriatric Medicine, Division of Health Sciences, Centre for Clinical Brain Sciences, University of Edinburgh, Edinburgh, UK. ${ }^{8}$ Anita Patel Health Economics Consulting Ltd, London, UK.

Received: 19 November 2018 Accepted: 24 July 2019

Published online: 13 August 2019

\section{References}

1. Healy $G$, et al. Breaks in sedentary time: beneficial associations with metabolic risk. Diabetes Care. 2008;31(4):661-6.

2. Owen NN, et al. Too much sitting: the population health science of sedentary behavior. Exerc Sport Sci Rev. 2010;38(3):105-13.

3. de Rezende $L$, et al. Sedentary behavior and health outcomes among older adults: a systematic review. BMC Public Health. 2014;14(1):333.

4. Ford ES, Caspersen CJ. Sedentary behaviour and cardiovascular disease: a review of prospective studies. Int J Epidemiol. 2012;41(5):1338-53.

5. Hoare $\mathrm{E}$, et al. The associations between sedentary behaviour and mental health among adolescents: a systematic review. J Behav Nutr Phys Act. 2016;13:108. DOl: https://doi.org/10.1186/s12966-016-0432-4.

6. Biddle S, et al. Too much sitting and all- cause mortality: is there a causal link? BMC Public Health. 2016;16:635.

7. Paul $L$, et al. Physical activity profiles and sedentary behaviour in people following stroke: a cross- sectional study. Disabil Rehabil. 2016;38(4):362-7.

8. Theou $\mathrm{O}$, et al. Association between sedentary time and mortality across levels of frailty. J de I'Association Medicale Canadienne. 2017; 189(33):E1056.

9. Tremblay MS, et al. Sedentary behavior research network ( SBRN) terminology consensus project process and outcome. Int J Behav Nutr Phys Act. 2017;14(75). DOI: https://doi.org/10.1186/s12966-0170525-8.

10. Shrestha N, et al. Effectiveness of interventions for reducing nonoccupational sedentary behaviour in adults and older adults: a systematic review and meta- analysis. Br J Sports Med. 2018. https://doi.org/10.1136/ bjsports-2017-098270.

11. Stephenson A, et al. Using computer, mobile and wearable technology enhanced interventions to reduce sedentary behaviour: a systematic review and meta- analysis. Int J Behav Nutr Phys Act. 2017;14(105). https://doi.org/1 0.1186/s12966-017-0561-4.

12. Boberska M, et al. Sedentary behaviours and health- related quality of life. A systematic review and meta- analysis. Health Psychol Rev. 2018;12(2):195-210.

13. Ekelund $U$, et al. Does physical activity attenuate, or even eliminate, the detrimental association of sitting time with mortality? A harmonised meta-analysis of data from more than 1 million men and women. Lancet. 2016;388(10051):1302-10.

14. Prince SA, et al. Correlates of sedentary behaviour in adults: a systematic review. Obes Rev. 2017;18(8):915-35.
15. Franco MR, et al. Older people's perspectives on participation in physical activity: a systematic review and thematic synthesis of qualitative literature. Br J Sports Med. 2015;49(19):1268.

16. Devereux-Fitzgerald A, et al. The acceptability of physical activity interventions to older adults: a systematic review and meta- synthesis. Soc Sci Med. 2016;158:14-23.

17. Excellence, N.I.f.H.a.c. Methods for the development of NICE public health guidance (third edition); 2012.

18. Thomas J, Harden A. Methods for the thematic synthesis of qualitative research in systematic reviews. BMC Med Res Methodol. 2008;8:45.

19. Software., N.q.d.a. QSR International Pty Ltd Version 10; 2014. Editor

20. Cousins SOB, Keating N. Life cycle patterns of physical activity among sedentary and active older women. J Aging Phys Act. 1995;3:340-59.

21. Biddle $\mathrm{SJH}$, et al. Reducing sedentary time in adults at risk of type 2 diabetes: process evaluation of the STAND ( sedentary time and diabetes) RCT. BMC Public Health. 2017;17(1). https://doi.org/10.1186/s12889-016-3941-9.

22. Britten L, Addington C, Astill S. Dancing in time: feasibility and acceptability of a contemporary dance programme to modify risk factors for falling in community dwelling older adults. BMC Geriatr. 2017;17(1):83.

23. Emadian A, Thompson J, Mixed A. Methods examination of physical activity and sedentary time in overweight and obese south Asian men living in the United Kingdom. Int J Environ Res Public Health. 2017;14(4):E348.

24. Ezeugwu VE, Garga N, Manns PJ. Reducing sedentary behaviour after stroke: perspectives of ambulatory individuals with stroke. Disabil Rehabil. 2017; 39(25):2551-8

25. Leask CF, et al. Co- creating a tailored public health intervention to reduce older Adults' sedentary behaviour. Health Educ J. 2017;76(5):595-608.

26. McEwan T, Tam-Seto L, Dogra S. Perceptions of sedentary behavior among socially engaged older adults. Gerontologist. 2017;57(4):735-44.

27. Smetaniuk T, et al. Physical activity and sedentary behaviour of master of physical therapy students: an exploratory study of facilitators and barriers. Physiother Can. 2017:69(3):260-70.

28. Van Dyck D, et al. Opinions toward physical activity, sedentary behavior, and interventions to stimulate active living during early retirement: a qualitative study in recently retired adults. J Aging Phys Act. 2017;25(2):277-86.

29. Chen YM. Perceived barriers to physical activity among older adults residing in long-term care institutions. J Clin Nurs. 2010;19(3-4):432-9.

30. Mabry RM, et al. Addressing physical inactivity in Omani adults: perceptions of public health managers. Int J Environ Res Public Health. 2014;17(3):67481.

31. Chastin $\mathrm{S}$, et al. Determinants of sedentary behavior, motivation, barriers and strategies to reduce sitting time in older women: a qualitative investigation. Int J Environ Res Public Health. 2014;11(1):773-91.

32. Guell C, et al. Keeping your body and mind active': an ethnographic study of aspirations for healthy ageing. BMJ Open. 2016;6(1):e009973. DOI: https:// doi.org/10.1136/bmjopen-2015-009973.

33. Grossman M, Stewart A. "You aren't going to get better by just sitting around": physical activity perceptions, motivations, and barriers in adults 75 years of age or older. Am J Geriatr Cardiol. 2003;12(1):33-7.

34. Matei $R$, et al. Acceptability of a theory- based sedentary behaviour reduction intervention for older adults ('On your feet to earn your seat'). BMC Public Health. 2015;15:606. https://doi.org/10.1186/s12889-015-1921-0.

35. Kolt GS, Paterson JE, Cheung WM. Barriers to physical activity participation in older Tongan adults living in New Zealand. Australas J Ageing. 2006;25(3):119-25.

36. Thomsen $\mathrm{T}$, et al. Sedentary behaviour in patients with rheumatoid arthritis: a qualitative study. Int J Qual Stud Health Well Being. 2015;10(1):28578.

37. Adams M, Gill D. Reducing sedentary behavior: active steps for overweight women. Women Sport Physical Act. 2015;23:9-18.

38. Martínez-Ramos E, et al. Prolonged sitting time: barriers, facilitators and views on change among primary healthcare patients who are overweight or moderately obese. PLoS One. 2015;10(6):e0125739.

39. Paxton $R$, et al. Breaking up sedentary behaviour perceptions from cancer survivors. Cancer Nurs. 2016;39(4):272-8.

40. Trinh $L$, et al. A qualitative study exploring the perceptions of sedentary behavior in prostate cancer survivors receiving androgen-deprivation therapy. Oncol Nurs Forum. 2015;42(4):398-406.

41. Damush TM, et al. Barriers and facilitators to exercise among stroke survivors. Rehabil Nurs. 2007;32(6):253.

42. Greenwood-Hickman MA, Renz A, Rosenberg DE. Motivators and barriers to reducing sedentary behavior among overweight and obese older adults. Gerontologist. 2016;56(4):660-8. 
43. Ball K, et al. How can socio-economic differences in physical activity among women be explained? A qualitative study. Women Health. 2006:43(1):93-113.

44. Shuval K, et al. Impediments and facilitators to physical activity and perceptions of sedentary behavior among Urban Community residents: the Fair Park study. Prev Chronic Dis. 2013;10:E177.

45. Teychenne M, Ball K, Salmon J. Promoting physical activity and reducing sedentary behavior in disadvantaged neighborhoods: a qualitative study of what women want (promoting physical activity in disadvantaged women). PLOS ONE. 2012;7(11):e49583.

46. Teychenne M, Ball K, Salmon J. Perceived influences on and strategies to reduce sedentary behavior in disadvantaged women experiencing depressive symptoms: a qualitative study. Ment Health Phys Act. 2011;4(2):95-102.

47. Deliens $T$, et al. Determinants of physical activity and sedentary behaviour in university students: a qualitative study using focus group discussions. BMC Public Health. 2015;15(1):201. DOl: https://doi.org/10.1186/s12889015-1553-4.

48. Keegan $\mathrm{R}$, et al. Auditing the socio-environmental determinants of motivation towards physical activity or sedentariness in work-aged adults: a qualitative study. BMC Public Health. 2016;16:442.

49. Curry WB, Duda JL, Thompson JL. Perceived and objectively measured physical activity and sedentary time among south Asian women in the UK. J Environ Res Public Health. 2015;12(3):3152-73. DOI: https://doi.org/10.33 90/ijerph120303152.

50. West R, van Stralen Maartje M, Michie S. The behaviour change wheel: a new method for characterising and designing behaviour change interventions. Implement Sci. 2011;6(1):42.

51. Stubbs B, Koyanagi A. Physical chronic conditions, multimorbidity and sedentary behavior amongst middle- aged and older adults in six low- and middle- income countries. Int J Behav Nutr Phys Act. 2017;14(147). DOl: https://doi.org/10.1186/s12966-017-0602-z.

52. Lawson PJ, Flocke SA. Teachable moments for health behavior change: a concept analysis. Patient Educ Couns. 2009;76(1):25-30.

53. Michie S. In: Atkins L, West R, editors. The behaviour change wheel : a guide to designing interventions. Sutton: Silverback Publishing; 2014. p. 2014.

54. Barnett I, van Sluijs EMF, Ogilvie D. Physical activity and transitioning to retirement:a systematic review: a systematic review. Am J Prev Med. 2012;43(3):329-36.

55. Palmer $\mathrm{V}$, et al. What do older people do when sitting and why? Implications for decreasing sedentary behavior. Gerontologist. 2018;15. https://doi.org/10.1093/geront/gny020.

56. Bronfenbrenner $U$. The ecology of human development: experiments by nature and design. Cambridge: Harvard University Press; 1979.

57. Chastin SFM, et al. The SOS-framework (Systems of Sedentary behaviours): an international transdisciplinary consensus framework for the study of determinants, research priorities and policy on sedentary behaviour across the life course: a DEDIPAC-study; 2016.

58. Dixon-Woods M, et al. Synthesising qualitative and quantitative evidence: a review of possible methods. J Health Serv Res Policy. 2005;10(1):45-53.

59. Campbell R, et al. Evaluating meta- ethnography: systematic analysis and synthesis of qualitative research. Health Technol Assess. 2011;15:43.

60. Aminian S, et al. Sit less and move more: perspectives of adults with multiple sclerosis. Disabil Rehabil. 2019;41(8):904-11.

61. Kinnett-Hopkins D, et al. The interpretation of physical activity, exercise, and sedentary behaviours by persons with multiple sclerosis. Disabil Rehabil. 2019;41(2):166-71.

62. Matson T, et al. Acceptability of a sitting reduction intervention for older adults with obesity. BMC Public Health. 2018;18(1):706. DOI: https://doi.org/1 0.1186/s12889-018-5616-1.

63. $\mathrm{Wu} \mathrm{H}$, et al. Breast cancer Survivors' experiences with an activity tracker integrated into a supervised exercise program: qualitative study. JMIR Mhealth Uhealth. 2019;7(2):e10820. DOl: https://doi.org/10.2196/10820

64. Webber SC, et al. Exploring physical activity and sedentary behaviour: perspectives of individuals with osteoarthritis and knee arthroplasty. Disabil Rehabil. 2018;18:1-8. DOI: https://doi.org/10.1080/09638288.2018.1543463.

65. Dontje $\mathrm{M}$, et al. Why older adults spend time sedentary and break their sedentary behavior: a MixedMethods approach using life- logging equipment. J Ageing Phys Act. 2018;26(2):259-66.

66. McGowan L, Powell R, French D. How acceptable is reducing sedentary behavior to older adults? Perceptions and experiences across diverse socioeconomic areas. J Aging Phys Act. 2019;18:1-11.
67. Palmer VJ, et al. What do older people do when sitting and why? Implications for decreasing sedentary behavior. Gerontologist. 2018;59(4): 686-97. DOl: https://doi.org/10.1093/geront/gny020.

68. Warren TY, et al. African American Women's perceived influences on and strategies to reduce sedentary behavior. Qual Health Res. 2018;28(7):1112-22.

69. Polit DF, Beck CT. Generalization in quantitative and qualitative research: myths and strategies. Int J Nurs Stud. 2010;47(11):1451-8.

\section{Publisher's Note}

Springer Nature remains neutral with regard to jurisdictional claims in published maps and institutional affiliations.
Ready to submit your research? Choose BMC and benefit from:

- fast, convenient online submission

- thorough peer review by experienced researchers in your field

- rapid publication on acceptance

- support for research data, including large and complex data types

- gold Open Access which fosters wider collaboration and increased citations

- maximum visibility for your research: over $100 \mathrm{M}$ website views per year

At BMC, research is always in progress.

Learn more biomedcentral.com/submissions 